\title{
Evaluating the Waste Incineration Process for Sustainable Development through Modelling, Logistics, and Simulation
}

\author{
Martin Straka $^{1 *}$, Andrea Rosova ${ }^{1}$, Marcela Malindzakova ${ }^{1}$, \\ Samer Khouri ${ }^{2}$, Katarina Culkova ${ }^{2}$ \\ ${ }^{1}$ Institute of Logistics, BERG Faculty, Technical University of Kosice, Kosice, Slovakia \\ ${ }^{2}$ Institute of Earth Resources, BERG Faculty, Technical University of Kosice, Kosice, Slovakia
}

Received: 16 October 2017

Accepted: 7 December 2017

\begin{abstract}
This article deals with research on the impact of waste incineration processes on the environment within a particular region by means of computer simulation and logistics principles. The area of interest for this case study considers the aspects of the practical application of using the above methods and principles in order to reduce the environmental impacts of the waste incineration process in the Slovak Republic. At the initial stage of simulation model design, it is necessary to establish a formalized scheme, which is the basis for creating the actual simulation model. Then in the next stage the simulation model is created by combining building blocks within the given simulation software. The simulation results show that incineration during a one-year period produces about 15,266 tons of plastic and electrical components, and will release about 590,000 GJ of energy and about 199,000 tons of steam and 287 tons of other emissions with only 3 milligrams of dioxins. The computer simulation method is used to analyse, and subsequently adjust and improve the waste incineration process in order to achieve the desired parameter values - specifically the amount of heat produced, and the amount of generated steam and air pollutants.
\end{abstract}

Keywords: waste incineration, environmental impacts evaluation, logistics, modelling, computer simulation

\section{Introduction}

The sharp increase in the amounts and the variety of available products on the market have also caused an increase in the amounts of different packaging and other elements that come with any given product. The large amounts of communal waste stem from different

*e-mail: martin.straka@tuke.sk anthropomorphic activities, and different aspects of human consumption cause an increased demand for effective waste disposal by incineration, separation, recycling, or organic processing.

The object of modelling and simulation is the material flow of municipal waste during its processing. The disposed waste and generated emissions have a significant impact on the environment. Therefore, the processes for monitoring and optimizing the waste treatment are of crucial importance to minimize the amounts of disposed waste and emissions as well as their 
negative impacts. The waste treatment companies do their best to ensure effective waste treatment (recycling) and to restrict environmental pollution. Modelling, simulation, and modern informatics offer some easyto-implement solutions in process automation for both small and big companies. The first step of modernization consists in analysing the existing systems for processing the data on emissions, their evaluation, and visualization to identify available technologies, development tools, techniques, and current trends in the data processing and is of high importance. The waste incineration process can be simulated to achieve better emissions control.

The technology of incineration systems has developed over the years and is currently in a state where this form of waste disposal can be environmentally friendly, with the added value of produced thermal energy [1]. The acquired thermal energy can then be used for heating purposes, or be transformed into electrical energy. An efficient incinerator is not only assessed by the amount of thermal energy utilization, but also by the levels of emissions and quality of the ash it produces [2]. The thermal energy has some significant advantages, such as the greatly reduced volume of waste; the disposal of fungi, bacteria, and germs; and the production of thermal power. There are, however, some disadvantages in terms of environmental impact, such as the production of various toxic gases. As it is highly unlikely that there should be occur any significant decrease in the amount of available products on the market and that the rate of consumption will not cease, one can safely forecast that there will be an increased demand for efficient waste disposal by incineration. Therefore, it is important to pay attention to the environmental protection aspects of waste disposal in incineration facilities. As the future development in this area can only be estimated based on the statistics and conditions from previous years, it is appropriate to apply computer simulation tools. On the other hand, considering that this issue involves flow management and streamlining of production processes, the implementation of logistics principles is also highly appropriate.

This appears to indicate a problem that is related to the effective use of means of computer simulation and principles of logistics for the needs solutions for reducing the environmental impacts of the waste incineration process in the Slovak Republic and thus ensure sustainable environmental development in the region.

Under the process of waste incineration one can understand a production system with its components, and facilities with their flows [3]. Due to large variations of waste types and difficulties in feed characterization (physical, chemical, and thermal properties), the incineration process meets great challenges in smooth operation, with substantial fluctuations of gas temperatures within the system [4]. The aim within this case study is to set up the system of waste incineration in a way where the negative effects of its activities and the associated environmental impacts are minimal. In an ideal case there would be no negative impacts whosoever. In terms of flow management of waste streams, it is suitable to utilise the logistics principles, modelling, and computer simulation to manage and effectively streamline the processing flows. According to the Council of Supply Chain Management Professionals [5], "Logistics management is that part of supply chain management that plans, implements, and controls the efficient, effective forward, and reverses flow and storage of goods, services, and related information between the point of origin and the point of consumption in order to meet customers' requirements. Logistics management is an integrating function, which coordinates and optimizes all logistics activities, as well as integrates logistics activities with other functions, including marketing, sales manufacturing, finance, and information technology."

The aim of this case study is to discuss the use of computer simulation and logistics for the management of waste incineration processes in the context of environmental protection. No less important is the combination of these three approaches within one cohesive methodological framework to achieve the most efficient waste incineration process within the region of interest, and thus to ensure in practice the long-term sustainable development of the environment.

\section{Theoretical Base}

\section{Logistics, Simulation, and Modelling in the Environment}

To achieve the highest production performance by maximizing efficiency, logistics at the strategic, tactical, and operational level defines and proposes actions that lead to the desired results using all available means of science and technology, economics, and computer science. By applying logistics, the companies are trying to reduce and minimize costs, thus trying to ensure market competitiveness. The aim of logistics is to create a single, integrated, optimized material flow that can be created by connecting the various parts of the system so that a continuous exchange of goods and services can be provided. Logistics is gradually evolving, and at the same time the views on its scope and level of influence are evolving [6]. The process of waste management is important for the health of the public, and for aesthetic and environmental reasons [7]. Waste processing and disposal and the streamlined processing flow performance can be provided by means of reverse logistics [8]. According to Hu et al. [9], "Reverse logistics is referred to as the process of logistics management involved in planning, managing, and controlling the flow of waste for either reuse or final disposal." According to the Council of Supply Chain Management Professionals, reverse logistics is defined as [5], "a specialized segment of logistics focusing on the movement and management of products and resources after the sale and delivery to the customer, and includes product returns for repair and/ or credit." 
The importance of reverse logistics increases along with the world population expansion [10-12], which causes proportional increases in the amount of generated waste that needs to be processed. When planning waste management, it is important to know that the choice of the waste treatment method affects processes outside the waste management system [13]. In waste treatment processes different materials and products are usually mixed [14]. Currently it is not possible to effectively manage material flows or waste flows without the use and application of principles, methods, and logistics systems. One of the available approaches to analysis, research, and streamlining of processes that can be used within the methodological apparatus of logistics is computer simulation.

Since the 1950s, simulation has undergone considerable transformation and rapid development. The simulation systems are tailored for the needs of companies by creating computer simulation models that reflect closely the systems to be simulated. Simulation systems make it possible to make quick adjustments in the generated models to reflect changes that may occur in the real system. Although simulation modelling is not a tool for obtaining the optimal solution, it does allow you to test different output decisions on the simulation model [15-16].

The model allows carrying out experiments to evaluate, analyse, and optimize the results that can be used for the real system. The simulation models developed through simulation systems like Simul8, EXTENDSIM, Tecnomatix Plant Simulation, Witness, and the like are object-oriented, work on the principle of discrete simulation [17-18], and are focused on events and processes. A significant part of the added value is represented by the professional animations that the simulation systems are able to generate [19].

If we want to understand the mechanisms associated with the waste incineration process, it is necessary to realize a significant amount of work. This is being approached by 3 work routes: plant/process (analysis), modelling and simulation, and other desk study [20]. Modern European incinerators are similar, with electricity production [21-22]. This incinerator system is the same in our case study in the Koksov-Baksa factory. Research of evaluation of logistics and waste incineration processes requires the application of simulation systems. Evaluating solid waste incineration is necessary for setting the whole system to efficiency level as the economic part and the technical part, too [23]. Effective waste incineration depends on the interaction of several factors. As planning for sustainable municipal solid waste management has to address several inter-connected issues such as landfill capacity, environmental impacts, and financial expenditure, it becomes increasingly necessary to understand the dynamic nature of their interactions [24-25]. Modelling and simulation are standards for research of solid waste incineration [26-29]. Understanding incinerator operations is a fundamental prerequisite for achieving of the maximum productivity of the technology and its efficiency [30]. This means that incineration activities will lead to a reduction in the produced flue gases. Researchers often use modelling and simulation as the best way to solve defined problems in the branch with waste incineration [31-32].

With these options available, different systems investigators are able to better understand the details of the operation within the system and to address them in terms of effective utilization of business resources. Such system analysis through computer simulations also address the conditions that are extreme, unlikely or impossible, and dangerous for the studied systems, people, nature, the environment, and where in reality it would not be possible to breach the defined standards. This makes it possible to understand the system operation also in risk conditions of risk and with certain probability estimate the behaviour of the system, or to define procedures that under certain ecological status must be implemented.

\section{Data for Computer Simulation Waste Incineration Design}

To build a complex simulation model of the waste incineration process within a particular region in Slovakia it is necessary to prepare and carry out a thorough analysis of the given system. The waste incineration plant in question can be classified as an industry in the area of the chemical processing with ties to the waste logistics. The input into the system is formed by hauling thousands of tons of communal waste from the city of Kosice and its surroundings. The main activity of the company is the disposal of imported waste by separation, sorting, and actual incineration.

Based on the results of the system analysis (in this case represented by the waste processing company) one can derive the following findings:

- Every year, 83,000 tons of waste get imported into the company after going through several levels of separation.

- The first separation is intended to separate plastics, electrical components, and wood from imported waste. The total volume of imported waste is composed of $19 \%$ plastic and electrical components and up to $10.00 \%$ wood in a variety of forms. The rest is represented by more than $71 \%$ of miscellaneous municipal waste.

- The second phase of separation occurs during the waste incineration phase, right after the actual burning. The resulting product of the incineration process and the subsequent separation consists of about $3 \%$ of ash, $90 \%$ of incinerated waste, and about $7 \%$ gases that arise in the process of waste incineration. The gases then pass through the filtration process, where the total volume of the flue gases consists of $65 \%$ steam and $35 \%$ other emissions.

- The third phase of separation relates to the separation of the resulting burned material and is focused on separating metals from the remaining solid burned 
material. There is about $2 \%$ of metal in the charred mass, and the remaining $98 \%$ is a clean clinker.

In terms of the overall process of waste incineration, some additional stations must be mentioned:

- One such station is the detection and measurement of the waste humidity level. If the waste is too wet, it is necessary to reduce overall waste moisture by mixing it with dry wood material. For this purpose, separated wood waste is acquired from the imported communal waste. If necessary, this dry wood is added into the wet waste mixture. The amount of wood material that needs to be added into the waste mixture depends on the overall level of annual rainfall. If there is a wet year with heavy rainfall, then more wood must be added. If there is a dry year, the wooden material needs to be added only occasionally. Overall, it can be stated that from the total volume of imported waste, $70 \%$ consists of dry waste without the need to add wood material and $30 \%$ consists of moist or wet waste, where there is a need to add dry wood into the mixture due to the high humidity levels.

- The second station that must mentioned follows the process of burning and magnetic separation. The incinerated waste is a hot material, called bottom ash or clinker. This clinker must be cooled by adding waste. For this activity about $10,000 \mathrm{~m}^{3}$ of water are used per year. The cooled clinker is then stored in a landfill within the company premises.

\section{Designing a Simulation Model for Analysing Waste Incineration}

\section{A Formalised Scheme and Block Diagram of Waste Incineration}

From the information above, and after analysing the activities in the case study company, a formalised scheme for incineration can be compiled (Fig. 1). The formalized scheme represents the overall system with its features and links. Elements of the system consist of individual parts, namely operations management. Between operations, there are relationships formed by elements of transport, management of waste flows, and by generated and separated material types like plastic, electrical, metals, fly ash, and clinker. Within the examined system is the main purpose for monitoring the amount of energy produced, of the amounts of released steam, and of dioxins.

Prepared formalized structure forms an important basis to create the actual simulation model. The individual parts of the formalized scheme are then subsequently

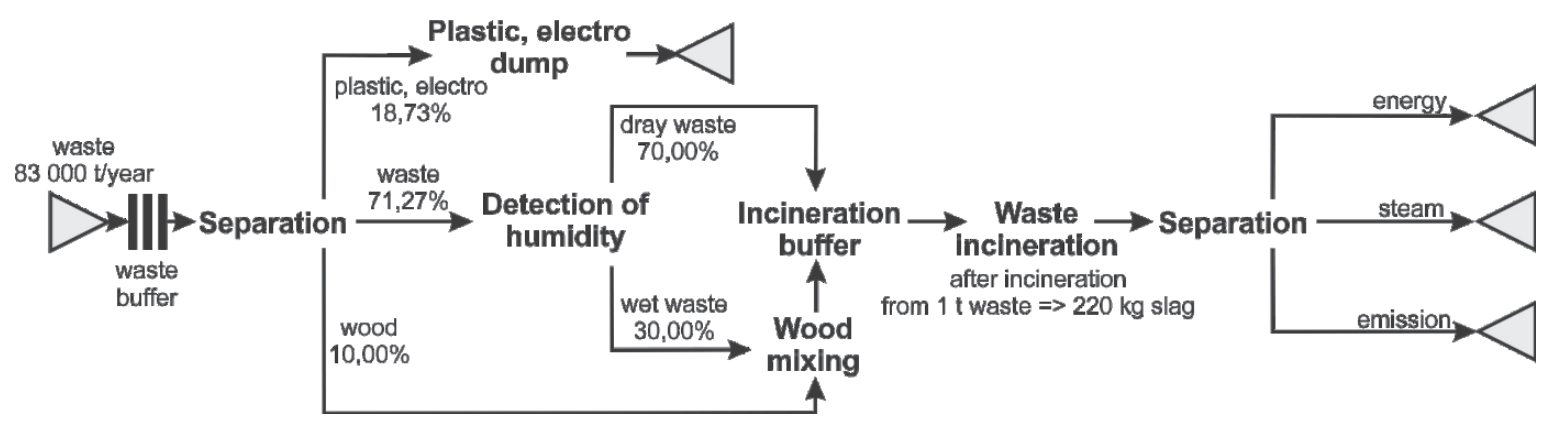

Fig. 1. Formalized scheme of incineration process activities within the case study company.

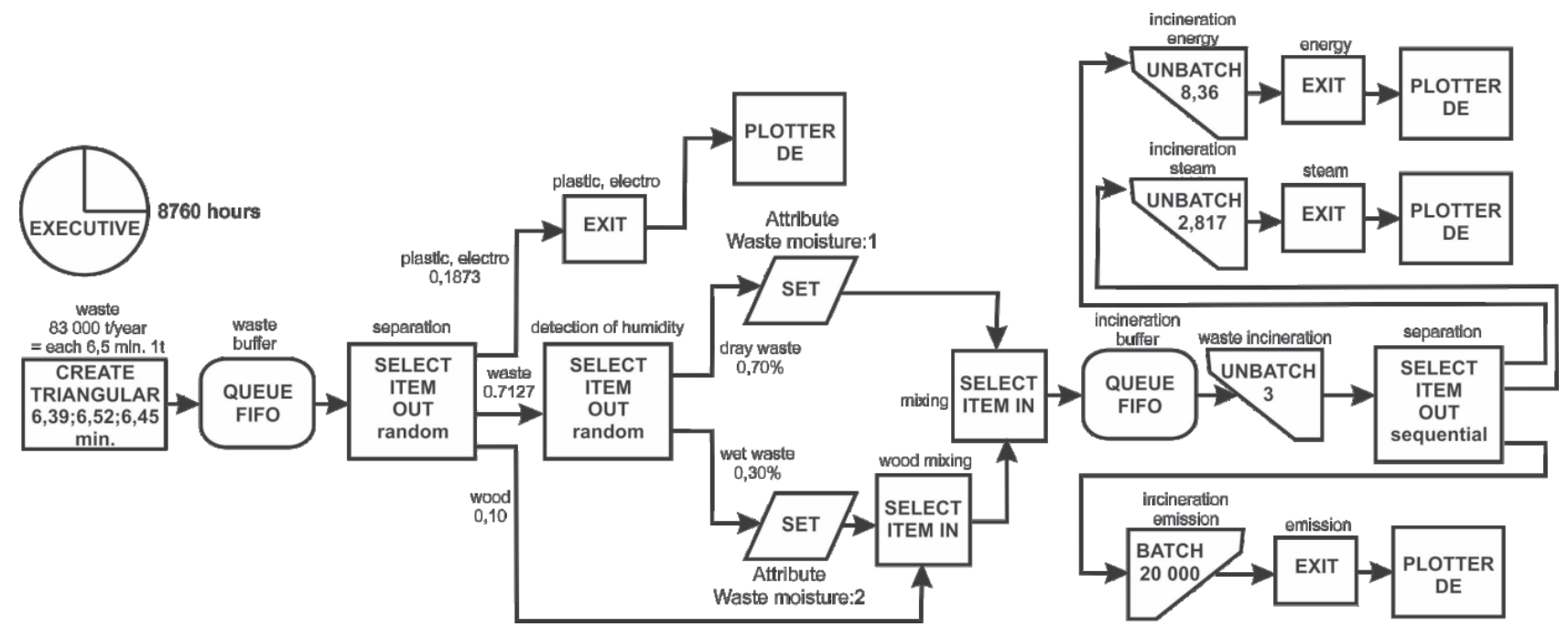

Fig. 2. Block diagram for the simulation system EXTENDSIM showing the incineration process activities within the case study company. 
replaced by the building blocks of the relevant simulation system. The creation of a simulation model consists of two parts:

The first part is represented by block diagrams of the respective simulation system (Fig. 2).

The second part is the actual simulation model with the implementation of research analysis and from data collection about the waste incineration process (Fig. 3).

Assembling a block diagram as the basis for the actual simulation model is an important step to prepare the data and information that are then used as the input to properly set the individual blocks within the simulation model.

The statistical data obtained from the case study company from the area of Kosice surroundings and Koksov-Baksa shows that the amount of waste supply into the company complex is 83,000 tons per year [3334]. A detailed analysis of the data shows that on average every 6 to 6.5 minutes another load of waste is brought into in the company complex in the amount of one ton. Therefore, the input of waste into the incineration process will be modelled by triangular distribution with the following parameters: from 6.39 minutes to 6.52 minutes with modus value set to 6.45 min per one ton of waste. The input waste is temporarily disposed of on a landfill from which it is further processed. The landfill is represented by the block "Queue." Next comes the first waste sorting - separating plastics, electrical components, and wood from the rest of waste for incineration. The block diagram for the simulation system EXTENDSIM the operation of separating the waste is represented by the simulation block "Select Item Out," which represents the identification of wet waste if there is the need to mix in a dry wood material.

Mixing wet waste with dry wood is modelled by the "Select Item In" block. Next follows the placement of waste into the container prior the incineration, from which with the help of a large crane it is collected and shifted into actual incineration. Modelling this container is achieved by the "Queue" block.

Next follows the separation into the monitored items, which are the energy released during incineration, the waste and water steam, and emissions. The emissions monitoring system is focused on identifying dioxins. These parts are modelled within the block diagram represented by the set of blocks "Unbatch"-"Select Item Out"-“Unbatch," and by "Unlatch"-"Select Item Out""Batch."

"Unbatch"-"Select Item Out" divide the total flow of waste produced into the monitored parts, namely energy, steams, and dioxins.

Block "Unbatch 8.36" represents waste incineration with the released energy. Physically and statistically it can be concluded that the incineration of one ton of waste releases 8.36 GJ of energy. "Unbatch" mimics the formation of energy during the simulation run.

"Unbatch 2.817" in the block diagram represents waste incineration with the release of water steam. Physically and statistically it can be stated that the incineration of one ton of waste releases 2.817 tons of steam. "Unbatch" mimics the release of water steam during the simulation run.

"Batch 20,000" in the block diagram represents the release of dioxin emissions during waste incineration. Physically and statistically it can be stated that about 3 milligrams of dioxins are produced, which means that for 20,000 tons of incinerated waste, about one milligram of dioxins is released. The "Batch" block simulates the generation of dioxins during the simulation run.

The prepared block diagram model of incineration represents the inactive part of the actual computer simulation model. Next follows the application of a block diagram for this particular simulation system. This application changes the inactive scheme into an active computer simulation model. The output achieved by the implementation of this active simulation model is data that represent the current state of the waste incineration process in the case study company. By adjusting parameters and by examining other influences on the system within the simulation model, one can define recommendations and improvements for operation of the waste incineration process in terms of their impact on the environment. By implementing the recommendations that are based on the computer simulation outputs, one can improve the area of waste incineration in terms of environmental performance and the economics of the company, but also in terms of the technical-technological equipment of the company, and last but not least in terms of the total logistics of the company. All the abovementioned aspects involve social and human aspects.

\section{Simulation Model Design of Waste Incineration}

The simulation model of the incineration plant consists of blocks (Fig. 3) that represent the monitored part. Each block of the simulation model has its own meaning and justification. However, not all the operations can be modelled by a single simulation block. Often a combination of simulation blocks must be used in a sequence corresponding to the real combination of the incineration process activities. A no less important part of the simulation model is the consistent parameter setting within the simulation model. The data used for the setting are retrieved from the outcomes of the analysis of the formalized scheme and from the block diagram.

Parts of the simulation model are characterized by a sequence of blocks that are interconnected by lines that determine the direction of the production flow. The main characteristics of the individual simulation blocks are defined by the position, by the icon and the name of the block, the block connectors, and the dialogue windows with operands and flows.

Each used block occupies a certain place located in the simulation model that represents the real studied system. The blocks themselves represent specific processes, facilities, or activities that together represent the actual 

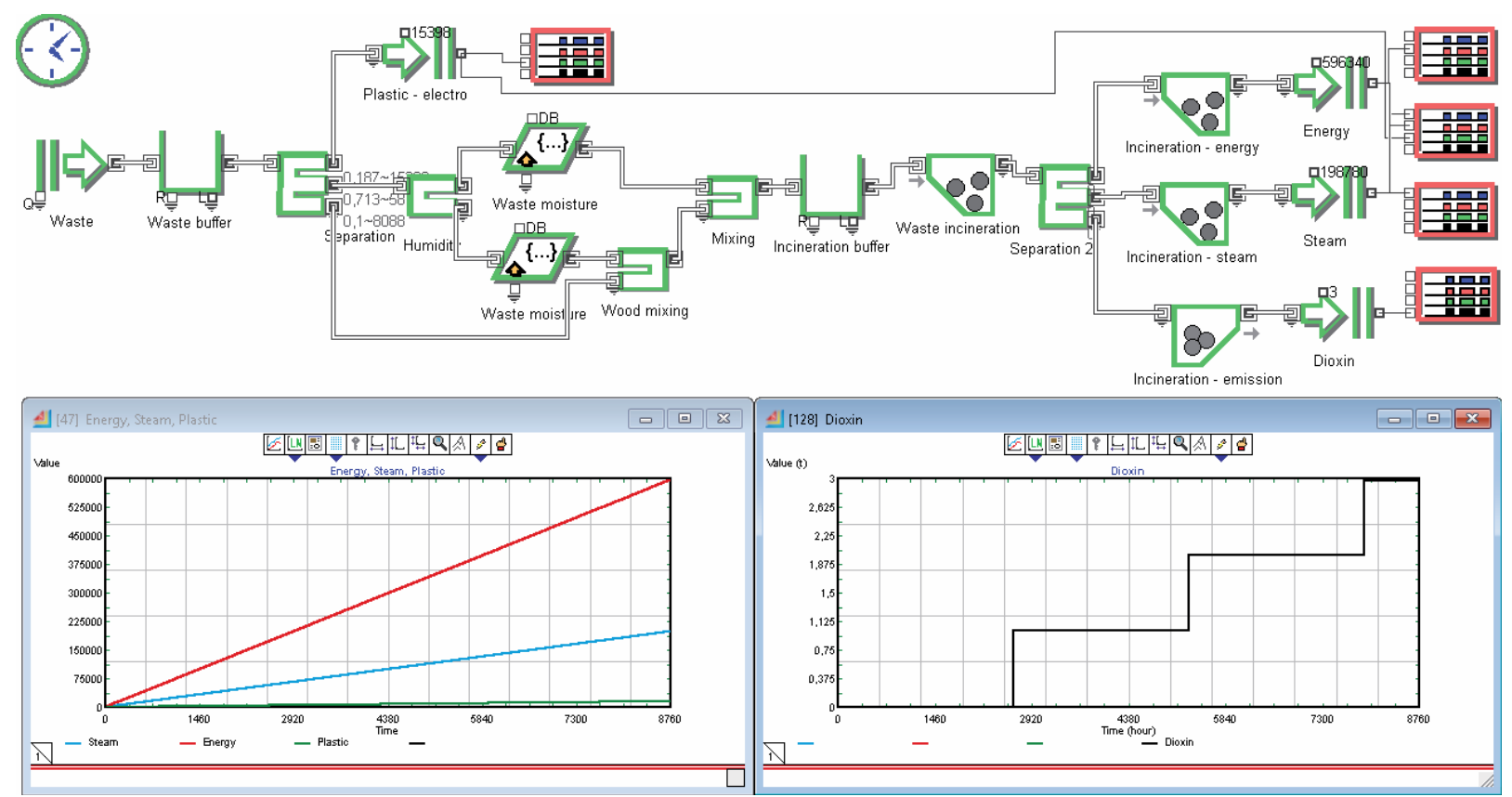

Fig. 3. Simulation model of waste incineration activities in the case study company with a focus on energy, steam, and dioxins.

model of the real system of the incineration plant within the case study company.

Each block has its own unique icon and its unique name that reflects its basic use within the model. The "Create" block represents the generator of the input requirements (the batches of waste in tons) into the model; the "Queue" block is used to create any kind of storage or a queue consisting of a series of requirements, with a defined input into the queue and an output from the queue. The block called "Exit" represents the output from the model for the requirements entering this block.

The block connectors enable us to connect the simulation blocks, taking care to observe the rule that you can always connect only the input connector with the output connector. By connecting 2 different blocks a logical sequence of blocks is created that reflects the real system.

Linking the block ensures the creation of a flow and enables its management and control. Connecting blocks must represent the real sequence of blocks, as it is in the examined system. By connecting 2 units via the connectors, a flow line gets created (double or single line) that uniquely defines a sequence of blocks and the direction of flow of requirements and values.

Dialogues and operands are specific items, block properties, which are characteristic for the individual blocks and necessary for the operation of individual blocks. By opening a dialogue window all the specific parameters and properties for the block can be displayed and subsequently specified.

\section{Environmental Assessment Based on Simulation}

The advantage of the computer simulations approach is that it is possible to examine conditions that would not be possible in reality, considering the safety of company workers. The simulation mimics the actual operation of the system for a period of one year, or 8,760 hours. The input of one element in the system represents the
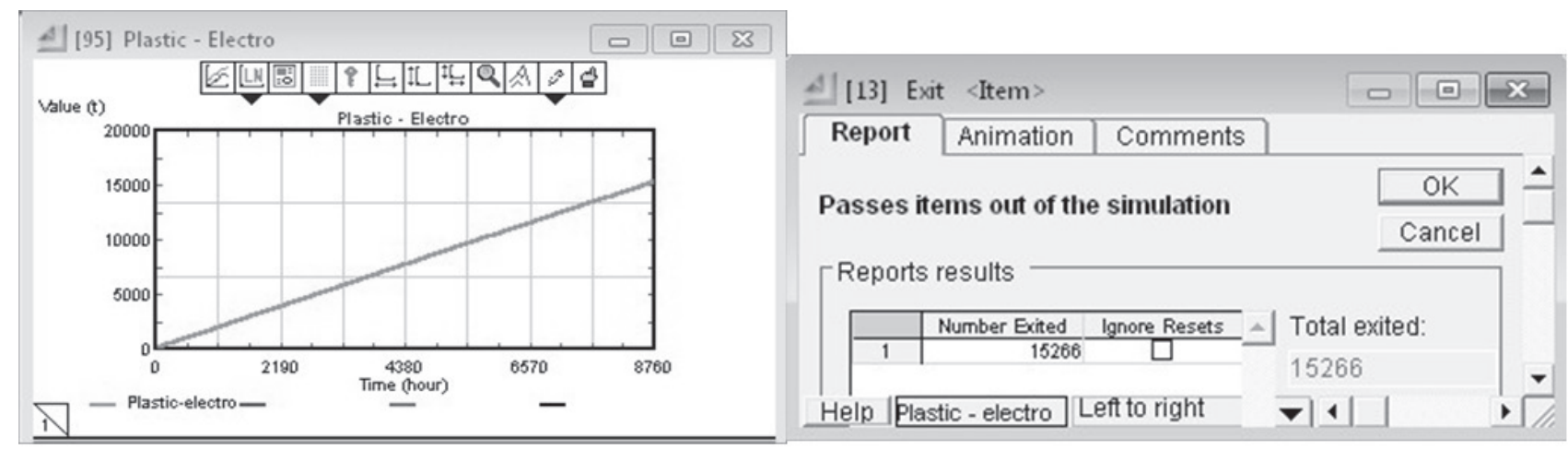

Fig. 4. Production of plastics and electronic materials from the separated waste in a one-year period. 
arrival of one ton of waste into the incineration plant. The simulation results show that incineration during a one-year period produces about 15,266 tons of plastic and electrical components (Fig. 4), and will release about 590,000 GJ of energy (Fig. 5) and about 199,000 tons of steam (Fig. 6) and 287 tons of other emissions with only 3 milligrams of dioxins (Fig. 7).

By examining the different settings for the waste incineration processes within the case study company in the Slovak Republic it can be stated that the overall reduction of the emissions amount, during and after the incineration process, is directly linked to a thorough waste separation process at the waste input. This point needs further investigation, especially considering the chemical composition of the input waste in terms of content. The findings indicate that many of the input waste components can be recycled without the need for actual incineration. This activity is highly dependent on intensive logistical activities and on the interest of other waste-processing companies to accept separated
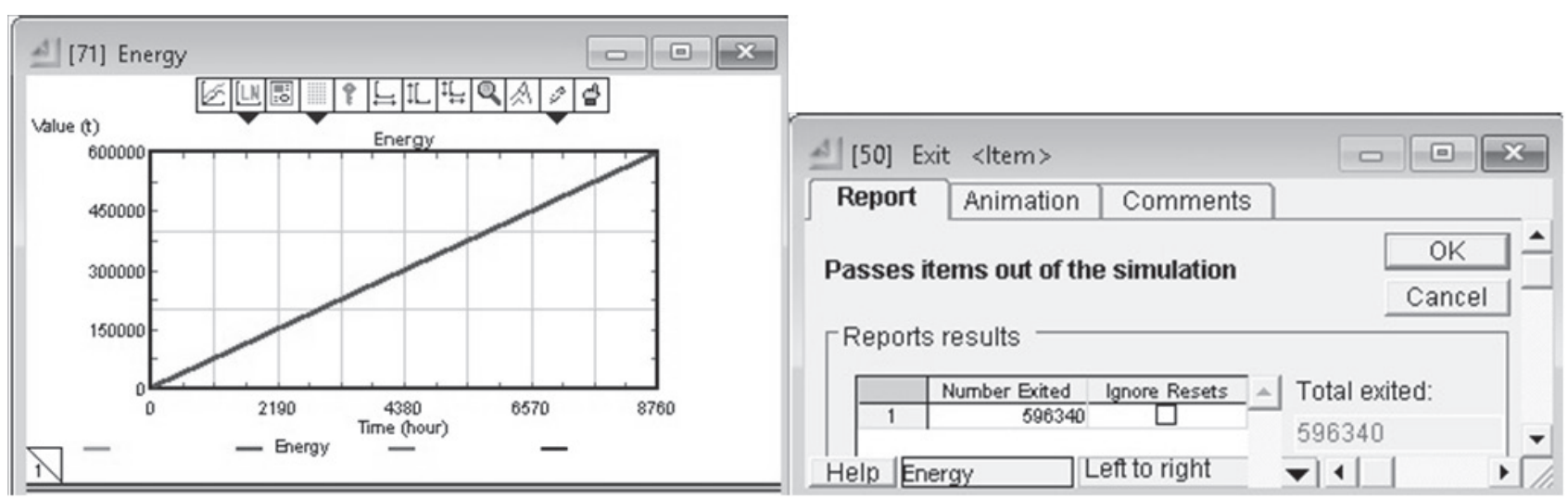

Fig. 5. The release of energy during incineration for a one-year period.

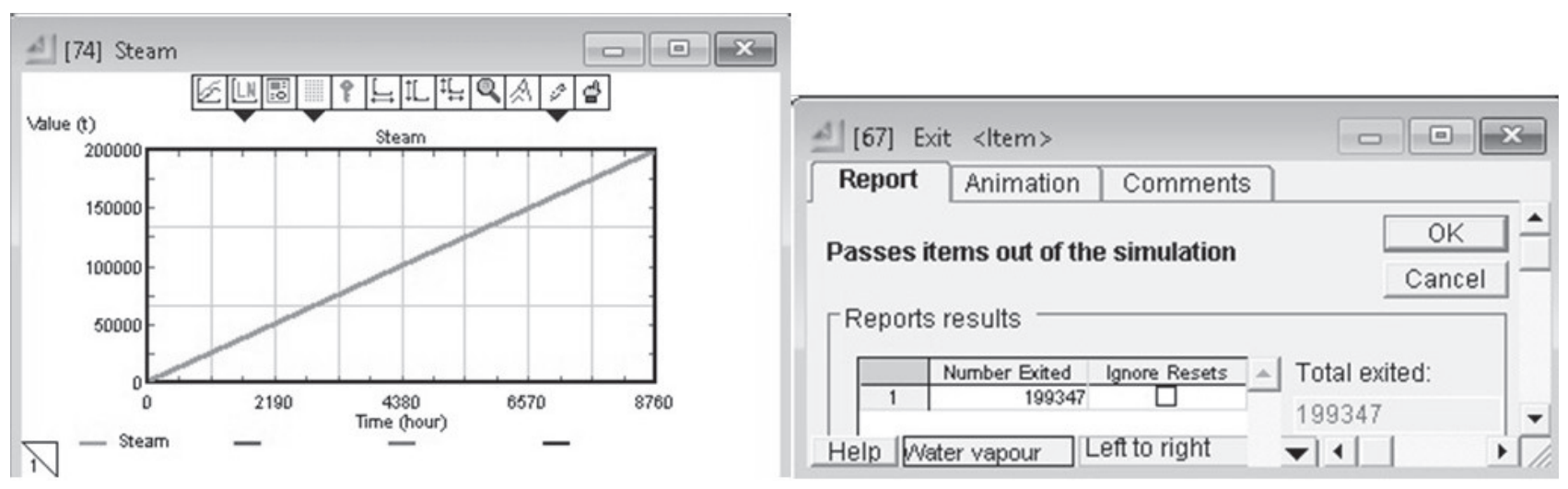

Fig. 6. The production of steam from waste incineration for a one-year period.

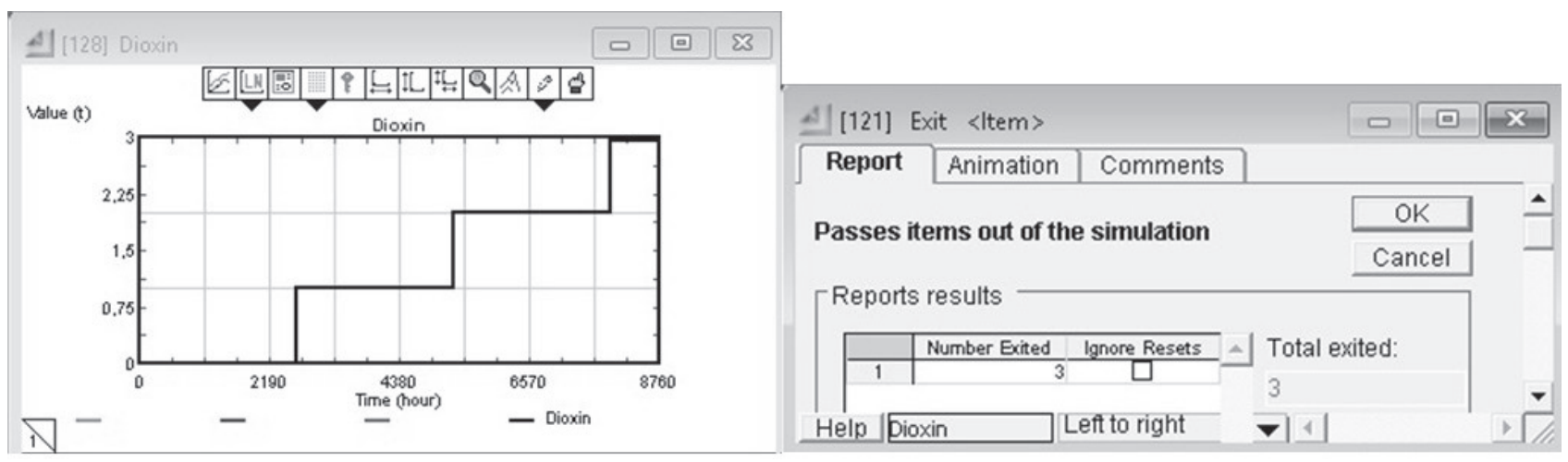

Fig. 7. The production of dioxins from waste incineration for a one-year period. 
materials. In conclusion, it is possible to present the overall simulation model of the entire waste processing and incineration plant.

The significant impact on the environment of municipal waste incineration is caused by the release of heavy metals and dioxins into the atmosphere. During the incineration process, the burning plastic packaging in the waste as a by-product releases the toxic dioxins. This substance belongs to one of most dangerous chemicals, which leaves lasting effects on all components of ecosystems, including the human body. The possible release of dioxins might occur in particular during:

- Incineration of municipal and of medical waste.

- Incineration of hazardous industrial waste.

- The process of manufacturing and incinerating PVC plastic.

The analysis of the simulation model outputs for the waste incineration process as well as real data from practice show that dioxin levels are at $3 \mathrm{mg}$ per year.

A significant element of municipal waste is plastic waste. Since within the city of Kosice and its surroundings included implementing increased promotion and other measures focusing on the waste separation, it can be concluded that the volume of toxic dioxins for the last 9 years did not exceed $3 \mathrm{mg}$ per year.

\section{Results, Discussion, and Conclusions}

Many research studies show that adverse environmental impacts can be minimized by reducing the amount of waste production (whether within the industrial or municipal sectors), and in this way also reduce the related emissions release. An essential step in waste reduction is the use of green materials as well as its secondary recovery, starting with the separation of waste.

Currently within the case study company, the operating costs are mainly affected by the composition of the input material for incineration, the amount of waste, the amount of used fuel, and the amount of natural gas needed to support the burning process. This indicates that a cost reduction is possible by ensuring a thorough separation of input materials. This was achieved by raising awareness among the population toward the sorting and secondary recovery of municipal waste, which indirectly also affected the total cost of fuel (less waste means fewer trips for waste transport vehicles) and also the costs of the actual incineration process due to the smaller amount of natural gas used. Therefore, throughout the entire product life cycle from raw material acquisition through production, use, and disposal at the end of product life (including the recycling and the final disposal - from cradle to grave), it is important to perform efficient sorting of related waste such as product packaging.

The results of these years of research for this case study show that the correct operation setting of waste processing, utilising the principle of logistics and modern technologies, while adhering to current legislation for the field of waste, can lead to achieving sustainable development of the environment within a given region.

The role of computer simulation to solve the case study problem consists of capturing the actual state of the system within the virtual environment of a computer simulation model and the implementation of this simulation model for testing of even extreme case scenarios. This provides important information about the behaviour of the system, which in reality cannot be otherwise obtained. There is a clear impact of logistics on the studied system, considering the efforts to streamline the waste flow within the plant operation. The main aspect relates to the use of logistical principles such as system approach, algorithms, planning, and global optimization method to solve a defined problem in the field of waste management.

Environmental assessments are an important step in building and implementing an environmental management system (EMS) that consists of the development and evaluation of the analysis followed by the adoption of measures to remedy deficiencies. The aim of analysis of the environmental situation within the region of the case study company is fact-finding in the field of environmental protection that affects production and non-production operations, and should be monitored:

- Manufacturing practice compliance of the company with the current legislation.

- The status of operational documentation.

- The status of internal and external communications in the area of the environmental protection.

- Responsibilities and liabilities between departments and employees.

Despite the amount of obtained results, there are still open questions and topics for further research such as:

- Is this approach also an applicable solution for managing hazardous waste?

- How will the impacts of the waste incineration process be affected by extreme climate change?

- What influence can the combination of a climate change and the continuous waste incineration process have on the populace?

Technological developments in the future will make it possible to recover up to $100 \%$ of waste without the need for incineration, which at the current state of technology "is not possible."

\section{Acknowledgements}

The submitted paper is a part of the "Implementation of new methods and forms of education based on applied research in the field of study 8.5.1 Logistics" KEGA 056TUKE-4/2018 projects funded by the Slovak Research and Education Grant Agency; "Implementation of a modular approach to monitoring quality parameters, taking into account the logistics of waste within the production plant" VEGA 1/0392/18, funded by the Slovak Research and Development Grant Agency; and 
"Research of methods and innovative technologies for integrated supply chain solutions as a significant source of competitive advantage for enterprises" VEGA 1/0400/18, funded by the Slovak Research and Development Grant Agency.

\section{References}

1. PAVLAS M., TOUŠ M., KLIMEK P., BÉBAR L. Waste incineration with production of clean and reliable energy. Clean Technologies and Environmental Policy, 13 (4), 595, 2011.

2. GOH Y.R., LIM C.N., ZAKARIA R., CHAN K.H., REYNOLDS G., YANG Y.B., SIDDALL R.G., NASSERZADEH V., SWITHENBANK J. Mixing, Modelling and Measurements of Incinerator Bed Combustion. Process Safety and Environmental Protection, 78 (1), 21, 2000.

3. FONTANILI F., VINCENT A., PONSONNET R. Flow simulation and genetic algorithm as optimization tools. International Journal of Production Economics, 64 (1-3), 91, 2000.

4. LOMBARDI F., LATEGANO E., CORDINER S., TORRETTA V. Waste incineration in rotary kilns: a new simulation combustion tool to support design and technical change. Waste Management \& Research. 31 (7), 739, 2013.

5. VITASEK K. CSCMP, CSCMP Glossary, Council of Supply Chain Management Professionals. Definitions compiled by: VITASEK K., Available online: http:// cscmp.org/imis0/CSCMP/Educate/SCM_Definitions_and Glossary_of_Terms/CSCMP/Educate/SCM_Definitions _ and Glossary of Terms.aspx?hkey $=60879588-\mathrm{f} 65 \mathrm{f}-4 \mathrm{ab} 5$ $8 \mathrm{c} 4 \overline{\mathrm{b}}-6878815 \mathrm{ef} 921$ (accessed on 29.10.2017).

6. STRAKA M. Logistics of distribution, How effectively to put product into the market. Logistika distribúcie. $1^{\text {st }}$ ed.; EPOS, Bratislava, Slovakia, 400, 2013 [In Slovak].

7. ŠOMPLÁK R., PAVLAS M., KROPÁČ J., PUTNA O., PROCHÁZKA V. Logistic model-based tool for policy-making towards sustainable waste management. Clean Technologies and Environmental Policy, 16 (7), 1275, 2014.

8. ABDESSALEM M., HADJ-ALOUANE A.B., RIOPEL D. Decision modelling of reverse logistics systems: selection of recovery operations for end-of-life products. International Journal of Logistics Systems and Management, 13 (2), 139, 2012.

9. HU T.L., SHEU J.B., HUANG K.H. A reverse logistics cost minimization model for the treatment of hazardous wastes. Transportation Research Part E: Logistics and Transportation Review, 38 (6), 457, 2002.

10. SEVIK H., CETIN M. Effects of Water Stress on Seed Germination for Select Landscape Plants. Polish Journal of Environmental Studies, 24 (2), 689, 2015.

11. BÁRTOVÁ P., HUSÁKOVÁ N. Reverse logistics and its variations, LOGI 2010, 370, 2010.

12. ZHANG Y.M., HUANG G.H., HE L. An inexact reverse logistics model for municipal solid waste management systems. Journal of Environmental Management, 92 (3), 522, 2011.

13. ERIKSSON O., CARLSSON REICH M., FROSTELL B., BJÖRKLUND A., ASSEFA G., SUNDQVIST J.-O., GRANATH J., BAKY A., THYSELIUS L. Municipal solid waste management from a systems perspective. Journal of Cleaner Production, 13 (3), 241, 2005.
14. CETIN M., SEVIK H. Measuring the Impact of Selected Plants on Indoor $\mathrm{CO}_{2}$ Concentrations. Polish Journal of Environmental Studies, 25 (3), 973-979, 2016.

15. CETIN M. Using GIS analysis to assess urban green space in terms of accessibility: case study in Kutahya. International Journal of Sustainable Development \& World Ecology, 22 (5), 420, 2015.

16. STRAKA M., MALINDZAKOVA M., ROSOVA A., TREBUNA P. The simulation model of the material flow of municipal waste recovery. Przemysl chemiczny, 95 (4), 773, 2016.

17. CETIN M., SEVIK H., SAAT A. Indoor Air Quality: The Samples of Safranbolu Bulak Mencilis Cave. Fresenius Environmental Bulletin. 26 (10), 5965, 2017.

18. CASSANDRAS CH.G., LAFORTUNE S. Introduction to discrete event systems, Springer Science \& Business Media, 2009.

19. BANKS J., CARSON II J.S., BARRY L. Discrete-event system simulation, fourth ed. Pearson, 2005.

20. MORRIN S., LETTIERI P., CHAPMAN CH., MAZZEI L. Two stage fluid bed-plasma gasification process for solid waste valorisation: Technical review and preliminary thermodynamic modelling of sulphur emissions. Waste Management, 32 (4), 676, 2012.

21. STANTEC, Waste to Energy, A Technical Review of Municipal Solid Waste Thermal Treatment Practices, Final Report. Prepard by Stantec for Environmental Quality Branch, British Columbia, Canada. Project number 1231, 2011.

22. CHEN C., JIN Y.Q., YAN J.H., CHI Y. Simulation of municipal solid waste gasification for syngas production in fixed bed reactors. Journal of Zhejiang University-Science A, 11 (8), 619, 2010.

23. GENG Y., TSUYOSHI F., CHEN X. Evaluation of innovative municipal solid waste management through urban symbiosis: a case study of Kawasaki. Journal of Cleaner Production, 18 (10-11), 993, 2010.

24. KOLLIKKATHARA N., FENG H., YU D. A system dynamic modeling approach for evaluating municipal solid waste generation, landfill capacity and related cost management issues. Waste Management, 30 (11), 2194, 2010.

25. LIN H., MA X. Simulation of co-incineration of sewage sludge with municipal solid waste in a grate furnace incinerator. Waste Management, 32 (3), 561, 2012.

26. CHEN CH., JIN Y-Q., YAN J-H., CHI Y. Simulation of municipal solid waste gasification in two different types of fixed bed reactors. Fuel, 103, 58, 2013.

27. CORDIOLI M., VINCENZI S., DE LEO G.A. Effects of heat recovery for district heating on waste incineration health impact: A simulation study in Northern Italy. Science of The Total Environment, 444, 369, 2013.

28. ERIKSSON O., BISAILLON M. Multiple system modelling of waste management. Waste Management, 31 (12), 2620, 2011.

29. GENTIL E.C., DAMGAARD A., HAUSCHILD M., FINNVEDEN G., ERIKSSON O., THORNELOE S., KAPLAN P.O., BARLAZ M., MULLER O., MATSUI Y., LI R., CHRISTENSEN T.H. Models for waste life cycle assessment: Review of technical assumptions. Waste Management, 30 (12), 2636, 2010.

30. FLEGNER P., KAČUR J., DURDÁN M., LACIAK M., STEHLÍKOVÁ B., PÁSTOR M. Significant damages of core diamond bits in the process of rocks drilling. Engineering Failure Analysis, 59 (January 2016), 354, 2016. 
31. MIAOMIAO N., YAJI H., BAOSHENG J., XINYE W. Simulation of Syngas Production from Municipal Solid Waste Gasification in a Bubbling Fluidized Bed Using Aspen Plus. Industrial \& Engineering Chemistry Research, 52 (42), 14768, 2013.

32. CHEN X., XI F., GENG Y., FUJITA T. The potential environmental gains from recycling waste plastics: Simulation of transferring recycling and recovery technologies to Shenyang, China. Waste Management, 31 (1), 168, 2011.

33. KOSIT J.S.C. Integrated permit 2067-25831/2007/ Mil/571070106 2015 [In Slovak].

34. MALINDZAKOVA M. Process approach - a synergy of influences to address issues of quality and environmental management. Habilitation thesis. F. BERG, Technical university of Kosice, 2015. 